\title{
Frequency of human papillomavirus types 16, 18,31 , and 33 and sites of cervical lesions in gynecological patients from Recife, Brazil
}

\author{
M.F.P.T. Baldez da Silva ${ }^{1}$, V. Guimarães ${ }^{2}$, M.A.R. Silva ${ }^{3}$, \\ C.M. Medeiros do Amaral ${ }^{3}$, W. Beçak ${ }^{4}$, R.C. Stocco ${ }^{4}$, A.C. Freitas ${ }^{3}$ \\ and S. Crovella ${ }^{3,5}$ \\ ${ }^{1}$ Laboratório de Citogenética, Universidade Estadual de Maringá, \\ Maringá, PR, Brasil \\ ${ }^{2}$ Unidade Ginecológica, Instituto Materno-Infantil Prof. Fernando Figueira, \\ Recife, PE, Brasil \\ ${ }^{3}$ Departamento de Genética, Universidade Federal de Pernambuco, \\ Recife, PE, Brasil \\ ${ }^{4}$ Laboratório de Genética, Instituto Butantan, São Paulo, SP, Brasil \\ ${ }^{5}$ Genetic Service IRCCS Burlo Garofolo Department of Reproductive and \\ Development Sciences, University of Trieste, Trieste, Italy
}

Corresponding author: M.F.P.T. Baldez da Silva

E-mail:mfbaldez@hotmail.com

Genet. Mol. Res. 11 (1): 462-466 (2012)

Received March 1, 2011

Accepted December 2, 2011

Published March 1, 2012

DOI http://dx.doi.org/10.4238/2012.March.1.3

\begin{abstract}
Human papilloma virus (HPV) is a well-established cause of cervical cancer. While many studies have been performed so far on HPV viral biology, mode of infection and prevention measures, scanty information is available on lesion sites of infected women and the incidence of viral types at specific locations. We looked for a possible relationship between the most common viral types (HPVs 16, $18,31,33)$ found in Recife, PE, Brazil, and lesion sites. We examined 396 HPV-positive women at the Gynecological Unit of the IMIP at Recife; 288 women were positive for HPV 16, 18, 31, or 33, present as
\end{abstract}


a single-virus type or as co-infection. HPV 16 was the most frequent virus type found in the vulva, vagina, uterine cervix-vagina, and uterine cervix. HPV 31 was the second prevalent virus type in vulva, vagina, uterine cervix-vagina, uterine cervix, and mole. HPVs 18 and 33 were present with similar frequencies in the mole-vulva region. Among the co-infections, HPV 16/18 and HPV16/31 were the most frequent in our study group, followed by HPV 16/33.

Key words: Human papillomavirus; Cervical lesions; Cervical cancer

\section{INTRODUCTION}

Human papilloma virus (HPV) is a well-established cause of cervical cancer. Indeed, oncogenic high-risk HPV (HR-HPV) genotypes are closely associated with more than $95 \%$ of cases of squamous cell carcinoma of the cervix (Chaturvedi, 2010). The association between HPV and lesions prior to cervical cancer has been reported by Ault (2006), and these lesions are known as skin moles.

The most common HPV types related to carcinomas and their precursor lesions are 16 and 18 (Broomall et al., 2010). Besides these virus types, others exist that are equally or more infectious, depending on the geographic region where they occur. Virus types 31 and 33 are the second and third most common types in the central and northeastern regions of Brazil (Lorenzato et al., 2000; Baldez da Silva et al., 2009).

Although HPV infection may occur in the cervix (Rama et al., 2008a), scanty information exists on the relationship between lesion sites and the prevalence of virus types.

Our study describes the relationship between lesion site and the virus type prevalent in patients from the "Instituto de Medicina Integral Prof. Fernando Figueira" (IMIP) located in Recife (PE), Northeast Brazil.

\section{MATERIAL AND METHODS}

We enrolled 396 females (average age of 23 years, range $=18-35$ ) at the Gynecological Unit of the IMIP in Recife. All patients lived within the metropolitan area of Recife, Pernambuco, Northeast Brazil. The importance of the study was explained to the patients who gave their written consent. Our study had the approval of the IMIP Ethics Committee. Inclusion criteria were positivity for HPV and clinical follow-up of at least 3 years. The same medical team always performed the sample collection, and smears were obtained from the uterine cervix, vulva and vagina.

The cervical-vaginal cytological test for lesions was performed on samples collected at different regions of the female reproductive apparatus (uterine cervix, vulva and vagina) regardless of the presence of visible lesions. Cytobrush smears were placed on glass slides, fixed in 95\% ethanol and stained with Papanicolaou method.

HPV detection was performed by PCR amplification, using generic primers MY09/11 following standard protocols (Rambout et al. 2007). We then amplified E6 and E7 HPV regions with specific PCR primers, reported by Karlsen et al. (1996) in order to detect the HPV $16,18,31$, and 33 genomes. 
The amplification protocol was as follows: PCR was performed in a total volume of $20 \mu \mathrm{L}$, containing $200 \mathrm{ng}$ DNA, $0.4 \mu \mathrm{M}$ of each specific primer; amplification master mix was composed of $2.5 \mathrm{U}$ Taq Polymerase, $200 \mathrm{nM}$ of each dNTP and $1.5 \mathrm{mM} \mathrm{MgCl}_{2}$.

PCR-specific amplification was performed using the GeneAmp 9700 thermal cycler (Applied Biosystems, Foster City, CA, USA). After an initial hold at $94^{\circ} \mathrm{C}$ for $5 \mathrm{~min}, 35 \mathrm{am}-$ plification cycles were run $\left(95^{\circ} \mathrm{C}\right.$ for $30 \mathrm{~s} ; 57^{\circ} \mathrm{C}$ to HPV 16 and $18,55^{\circ} \mathrm{C}$ to $\mathrm{HPV} 31$ and 33 , both for $30 \mathrm{~s}$, and $72^{\circ} \mathrm{C}$ for $1 \mathrm{~min}$ ), followed by the final elongation step at $72^{\circ} \mathrm{C}$ for $10 \mathrm{~min}$. Amplicons were visualized by UV light after electrophoresis on a $2.5 \%$ agarose gel stained with ethidium bromide.

Patients were stratified for the presence of HPV 16, 18, 31, and 33 alone and co-infections with more than one viral type, namely $16 / 18,16 / 31,16 / 33,16 / 31 / 33,16 / 18 / 31$, and 18/31.

\section{RESULTS}

Among the $396 \mathrm{HPV}$-positive patients included in our study, 288 women were positive for HPV 16, 18, 31, and 33, present as a single-virus type or as co-infection. Thus, 108 subjects not presenting HPV 16, 18, 31, and 33 were excluded from the analysis.

After HPV typing, we analyzed the relationship between patients' lesion site and virus type. The total number of samples per site was as follows: vulva (65), vagina (7), uterine cervix-vagina (121), uterine cervix (87), mole (2), mole-vulva (6).

Table 1 summarizes the frequencies of HPV types in the 288 women analyzed as well as the localization of different HPV types at distinct lesion sites.

Table 1. Analysis of 288 females positive for one or more HPV types, with site of lesion removal and its
relationship with virus types under analysis.
\begin{tabular}{lccccccr}
\hline Virus type/lesion site & Vulva & Vagina & Uterine cervix-vagina & Uterine cervix & Mole & Mole-vulva & Total \\
\hline 16 & $37(56.92 \%)$ & $4(57.14 \%)$ & $79(66.94 \%)$ & $43(49.42 \%)$ & $1(50 \%)$ & $2(33.34 \%)$ & 166 \\
18 & 0 & 0 & $2(1.69 \%)$ & $1(1.14 \%)$ & 0 & $1(16.67 \%)$ & 4 \\
31 & $9(13.84 \%)$ & $1(14.28 \%)$ & $11(9.32 \%)$ & $12(13.79 \%)$ & 0 & $1(16.67 \%)$ & 34 \\
33 & 0 & 0 & $2(1.69 \%)$ & $4(4.59 \%)$ & 0 & 0 & 6 \\
$16 / 18$ & 0 & $2(28.57 \%)$ & $2(1.69 \%)$ & 0 & 0 & 0 & 4 \\
$16 / 31$ & $15(23.07 \%)$ & 0 & $9(7.62 \%)$ & $24(27.58 \%)$ & $1(50 \%)$ & $2(33.34 \%)$ & 51 \\
$16 / 33$ & $3(4.61 \%)$ & 0 & $9(7.62 \%)$ & $2(2.30 \%)$ & 0 & 0 & 14 \\
$16 / 31 / 33$ & 0 & 0 & $3(2.54 \%)$ & 0 & 0 & 0 & 3 \\
$16 / 18 / 31$ & 0 & 0 & 0 & $1(1.14 \%)$ & 0 & 0 & 1 \\
$18 / 31$ & $1(1.53 \%)$ & 0 & $4(0.86 \%)$ & 0 & 0 & 0 & 5 \\
Total & 65 & 7 & 121 & 87 & 2 & 6 & 288 \\
\hline
\end{tabular}

Uterine cervix-vagina indicates intermediate region between uterine cervix and vagina. Mole-vulva indicates intermediate region between uterine mole and vulva.

The most frequent virus type found was HPV 16, present in 56.92\% of samples obtained from the vulva, $57.14 \%$ samples from the vagina, $66.94 \%$ from the uterine cervix-vagina, and $49.42 \%$ from the uterine cervix. HPV 31 was found in $13.84 \%$ of samples obtained from the vulva, $14.28 \%$ samples from the vagina, $9.32 \%$ from the uterine cervix-vagina, and $13.79 \%$ from the uterine cervix.

HPV 16/31 was the most frequent among the co-infections, where it was present in the vulva (23.07\%), uterine cervix-vagina (7.62\%) and uterine cervix (27.58\%). 


\section{DISCUSSION}

HPV belongs to a heterogeneous group of DNA viruses able to infect the skin and mucosa of several regions of the human body (Castro et al., 2009). Although approximately 45 different types infect the anus-genital region, HPV 6, 11, 16, and 18 account for most HPV lesions in this region (Park and Androphy, 2002; Muñoz et al., 2003).

Samples from patients may be obtained from different sites, depending on the localization of the lesion. Some lesions are located in the vulva, vagina, moles, and uterine cervix. Lesion samples at specific sites of the reproductive apparatus are sometimes difficult to obtain. They are thus sampled intermediately, or rather, from transition zones between two or more sites such as mole-vulva and/or uterine cervix-vagina.

In our study, we report the frequency of HPV types at different localizations, namely vulva, vagina, uterine cervix, mole, and intermediate regions, in a group of gynecological patients from Recife, Northeast Brazil. HPV 16 was the most frequent virus type, present in the vulva, vagina, uterine cervix-vagina, and uterine cervix. The second most prevalent virus type was HPV 31.

When we consider the most prevalent virus type (HPV 16) in our study group from Recife, lesions characterized by different extension and severity were present at any site of the reproductive apparatus. On the other hand, HPV 31, the second most prevalent virus in our study group, was present in the same regions as HPV 16, but it was never found in genital moles. HPV 18 and 33 were less frequent and behaved like HPV 31, since they did not occur in genital moles. When comparing the localization of HPV 33 and 18, the latter occurred more frequently in uterine cervix-vagina region.

We then considered virus co-infections, and we observed that the combination HPV16/31 was the most frequent in our study group, followed by co-infection HPV 16/33.

Co-infection 16/31 was more severe since it occurred in the vulva, uterine cervix-vagina, uterine cervix, moles, and mole-vulva at a higher rate when compared to the other co-infections.

When analyzing the distribution of HPV types at different locations in the reproductive apparatus of the 288 women enrolled in our study, we have to bear in mind that there was a rather low number of cases of mole or vulva-mole lesions, and thus, the results obtained for these regions should be considered cautiously. However, we demonstrated that in our study population from Recife, the most frequent HPV type is 16 followed by 31 .

Most infections are asymptomatic and may be clinically present in the form of an exophytic lesion. Infection may also have a subclinical form and may be visible only using magnification techniques, with reagents such as acetic acid. Types 16, 18, 31, 33, 35, 45, 51, 52,56 , and 58 were occasionally found in a clinical form of infection (genital moles) and have been associated with external lesions (vulva, penis and anus), with intra-epithelial or invasive neoplasm in the uterine cervix and vagina (Giuliano and Palefsky, 2009).

When found in the external genitalia, they are associated with in situ carcinoma of squamous cells, bowenoid papulosis, Queyrat's erythroplasia, and Bowen's disease of the genitals. Patients with genital moles may be infected simultaneously by several types of HPV. Types 6 and 11 are rarely associated with invasive carcinoma of squamous cells of the external genitalia (Derchain and Sarian, 2007).

Other authors also report that, as a rule, high-risk HPVs, which may include virus types $16,18,31$, and 33 , generally infect the uterine cervix, vulva, vagina, penis, and anus (Rama et al., 2008b). 
Consequently, in the case of infections with one or more types of papillomavirus, HPV 16, followed by human papillomavirus 31, involves more infection sites. Our findings show that, when dealing with papillomavirus 16 in females from Recife, lesions may appear in any site of the reproductive apparatus, although HPV 31 does not merely exist in moles. However, when there is combined infection 16/31, lesions may exist at any site, which demonstrates the great diversity of infection sites when compared to those of other virus types.

Since the number of patients analyzed in our study is quite small (i.e., 288), our results should be considered as preliminary, just giving an indication about the most frequent HPV type (the 16) found in the 288 women from Recife, but not being capable of correlating virus type with the site of the lesion.

Further studies with a greater number of patients from the same geographical area are mandatory. The current research is a contribution to medical care to the population of Recife and to research centers studying human papillomavirus.

\section{REFERENCES}

Ault KA (2006). Epidemiology and natural history of human papillomavirus infections in the female genital tract. Infect. Dis. Obstet. Gynecol. 2006: 1-5.

Baldez da Silva MF, Chagas BS, Guimaraes V, Katz LM, et al. (2009). HPV31 and HPV33 incidence in cervical samples from women in Recife, Brazil. Genet. Mol. Res. 8: 1437-1443.

Broomall EM, Reynolds SM and Jacobson RM (2010). Epidemiology, clinical manifestations, and recent advances in vaccination against human papillomavirus. Postgrad. Med. 122: 121-129.

Castro TM, Peixoto PG, Bussoloti IF, Nascimento VX, et al. (2009). Detecção de HPV na mucosa oral e genital pela técnica PCR em mulheres com diagnóstico histopatológico positivo para HPV genital. Rev. Bras. Otorrinolaringol. 75: $167-171$.

Chaturvedi AK (2010). Beyond cervical cancer: burden of other HPV-related cancers among men and women. J. Adolesc. Health 46: S20-S26.

Derchain SFM and Sarian LOZ (2007). Vacinas profiláticas para o HPV. Rev. Bras. Ginecol. Obstet. 29: 281-284.

Giuliano A and Palefsky J (2009). Quadrivalent HPV Vaccine Efficacy Against Male Genital Disease and Infection. In: 25th International Papillomavirus Conference Clinical and Educational Workshop, Malmö.

Karlsen F, Kalantari M, Jenkins A, Pettersen E, et al. (1996). Use of multiple PCR primer sets for optimal detection of human papillomavirus. J. Clin. Microbiol. 34: 2095-2100.

Lorenzato F, Ho L, Terry G, Singer A, et al. (2000). The use of human papillomavirus typing in detection of cervical neoplasia in Recife (Brazil). Int. J. Gynecol. Cancer 10: 143-150.

Muñoz N, Bosch FX, de Sanjosé S, Herrero R, et al. (2003). Epidemiologic classification of human papillomavirus types associated with cervical cancer. N. Engl. J. Med. 348: 518-527.

Park RB and Androphy EJ (2002). Genetic analysis of high-risk E6 in episomal maintenance of human papillomavirus genomes in primary human keratinocytes. J. Virol. 76: 11359-11364.

Rama CH, Roteli-Martins CM, Derchain SFM, Longatto-Filho A, et al. (2008a). Prevalência do HPV em mulheres rastreadas para o câncer cervical. Rev. Saúde Pública 42: 123-130.

Rama CH, Roteli-Martins CM, Derchain SFM, Longato-Filho A, et al. (2008b). Rastreamento anterior para câncer de colo uterino em mulheres com alterações citológicas ou histológicas. Rev. Saúde Pública 42: 411-419.

Rambout L, Hopkins L, Hutton B and Fergusson D (2007). Prophylactic vaccination against human papillomavirus infection and disease in women: a systematic review of randomized controlled trials. CMAJ 177: 469-479. 